\title{
Serological Diagnosis of Salmonella typhi in DHQ (District Head Quarter Hospital) of Charsadda, City of Kp Pakistan 2015-2016
}

\author{
Unays Siraj, Waqas Ahmad Shams", Gauhar Rehman, Sadaf Niaz \\ Department of Zoology, Abdul Wali Khan University Mardan, Khyber Puktunkhwa, Pakistan \\ Email address: \\ Wshams89@gmail.com(W.A. Shams) \\ ${ }^{*}$ Corresponding author
}

To cite this article:

Unays Siraj, Waqas Ahmad Shams, Gauhar Rehman, Sadaf Niaz. Serological Diagnosis of Salmonella typhi in DHQ (District Head Quarter Hospital) of Charsadda, City of Kp Pakistan 2015-2016. Computational Biology and Bioinformatics. Vol. 6, No. 1, 2018 , pp. $21-24$. doi: $10.11648 /$ j.cbb.20180601.12

Received: February 16, 2018; Accepted: March 16, 2018; Published: April 19, 2018

\begin{abstract}
Typhoid fever has a prominent as a perilous illness in Asia with almost $93 \%$ of worldwide cases has been underwritten by this region. Being a critical cause for an ailment and passing in creating nations where safe water supply, natural sanitation and sustenance cleanliness is not ideal. Typhoid remains a communicable disease found both male and female. It occurs due to the systematic infection of mainly via Salmonella typhi. An epidemiological model aimed at immediate and round about transmission of typhoid is planned and examined. The fundamental number is figured out. This cross-sectional study was carried out to determine the prevalence of typhoid fever in 4253 consecutive patients with fever and symptoms clinically compatible with typhoid fever to verify recent estimates of a high prevalence of typhoid fever in individuals living in the Charsadda. 923 patients show the positive result, 476 were males \& 487 females in the total of 4253. The ratio of positive result is considerable higher in females as compare to men.
\end{abstract}

Keywords: Typhoid Fever, Salmonella typhi, Charsadda, KP, Pakistan

\section{Introduction}

Salmonella typhi is a Gram-negative, facultative anaerobic, rod formed in addition to motile through peritrichous flagella. Salmonella belong to family Enterobacteriaceae, medically is notorious pathogen for equally, animals and Human being, Salmonella forms a multifaceted group of bacteria consisting of two species as well as six subspecies in addition comprise more than 2,579 species [1].

The disease is transmitted by feco-oral course or pee oral course, which more specifically through hands ruined with defecation or pee of cases or transporters or by implication by ingestion of tainted water, drain, sustenance or else through flies. It's outrageous summed up a disease of the reticuloendothelial framework, intestinal lymphoid tissue and the trouble bladder. Brooding period usually, might be as short as 3 days or the length of 21 days relying on the capacity of the inoculums and milder symptoms like fever, headache, constipation malaise, anorexia and diarrhea but server symptoms are gut perforation, encephalitis and in severe condition death has been frequently reported [2].

In 2003 a study conducted that in Pakistan water-borne infections claim 250,000 deaths each year among, in which Typhoid fever is the principal cause [3]. Typhoid Fever is encountered systematic disease caused with a human by the ingestion of polluted food and water the only known reservoir host of infection is human and it's actually very challenging to break down the chain of transmission. Infection of Salmonella is common in summer months [4] A remarkably comparable yet frequently less serious illness is generated by $S$. paratyphi A, B and at times C. Salmonella typhi, a very familiar human specific pathogen that around 50 000 years back, has astounding components for ingenuity in its host. Worldwide ratio of typhoid fever is every year is 16 million disease and 600,000 passing cases. Enteric fevers 
cause 200,000 passing away and per year 22 million illnesses, with the highest incidence happening in Southeast and Central Asia [5]. It's endemic in many parts of Central America South, East Asia and the Indian subcontinent. Typhoid fevers remain mostly related with regions with high poverty and under development. The sickness is projected to have brought on 21.6 million illnesses and 216,500 passing's all-inclusive in the year of 2000, influencing all ages but Salmonella typhi is furthermost likely to get in kids, age lower than five years [6]

World Health Organization in 2014 testified about 21 million typhoid illnesses in which 0.2 million typhoid-related deaths around the globe. The overall extraordinary occurrence of typhoid is introduced in creating nations and fundamentally high in Asia. In 2008, it was accounted that among Asian nations India and Pakistan had a high occurrence rate of enteric fever, than Indonesia, China and Vietnam Table 1.1.

Another study focused in Bangladesh amid in 2001 confirmed that among fibril ailment typhoid fever was the around $72.7 \%$. In 2010 reported that $88 \%$ typhoid fever between progeny of semi-urban ranges of Bangladesh and in Iran the ratio was endemic near about $54 \%$ in the year of 2010 [7]. Especially it predominant in developing nations, because the absence of training, Public Health and disappointment in common cleanliness [8]. Among years ago diverse category of methods are aimed for the determination, Rapid diagnostic Typhoid kits are used for finding of immunoglobulin $\mathrm{G}$ ( $\mathrm{IgG})$ \& Immunoglobulin $\mathrm{M}$ (IgM) antibodies, against of immunogenic, outer membrane protein sugar antigen (OMP) specific for Salmonella enterica Serover typhi immobilized on the nitrocellulose membrane.

\section{Methods \& Materials}

To determine the prevalence typhoid fever, all cases diagnosed primarily as typhoid fever in DHQ (District Hospital Quarter) of Charsadda, from Jan 2016 to Dec 2016 estimated timing are one year. We gathered blood from 4253 from patients both male \& female, age limit from 6 to 70 , primary, Secondary School level students, reproductive male $\&$ female included. From each, a proper and appropriate consent was taken $\&$ in the case of a child from his/her guardian at the time of specimen collection.

About 3cc blood collected through syringe venipuncture technique from patient $\&$ after proper clotting, serum was separated by centrifuge at $3000 \mathrm{rpm}$ for five minutes, after this Typhidot ${ }^{\circledR}$ test kit was used to define $\operatorname{IgG} \& \operatorname{IgM}$. Take out test card from foil bag and place it horizontally, $10 \mu \mathrm{l}$ add of complete blood/serum on S (Sample) point afterward this sample is entirely absorbed then, enhance two droplets of dilute provided with the assay to the sample hole. 15 minutes postponement and understand results, where the control band does not seem, are considered the invalid result.

\section{Result}

In this study suspect, patients was enrolled. The age of subjects ranged from six to seventy years. Suspected patient's serums were verified for the detection of typhoid fever IgM \& IgG antibodies. The test revealed that in total 4253 patients. Test displayed that 963 were show result Positive and 3290 displayed the Negative result. In 963 positive result, 476 were males $\& 487$ females. It's mean according to this paper ratio of typhoid in the female is large and increase as compared to men. Figure 1.1.

In Month wise infection we also calculated Typhoid fever, there is little bit increase and decrease occur in infection both males and females due to some climatic changes, but the ratio of Typhoid fever is more estimated and testified in the month of May as compare to the other months. (Figure1) (Table 1)

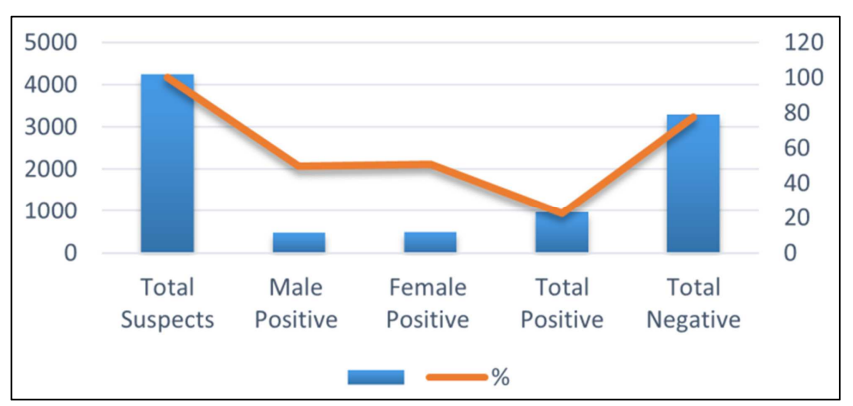

Figure 1. Gender wise incidence per population.

Table 1. Year wise incidence per population.

\begin{tabular}{|c|c|c|c|c|}
\hline \multirow{2}{*}{ Country } & Ochiai et al., 2008 & \multirow{2}{*}{ Population } & Ochiai et al., 2005 & \multirow{2}{*}{ Population } \\
\hline & Incidence per 100,000 Population & & Incidence per 100,000 Population & \\
\hline Pakistan & 451.7 & 101937 & 394.2 & 15219 \\
\hline India & 214.2 & 59946 & 136.7 & 57075 \\
\hline Indonesia & 81.7 & 160261 & 82,4 & 160257 \\
\hline China & 15.3 & 112889 & 15.2 & 98376 \\
\hline Vietnam & 21.3 & 281781 & - & - \\
\hline
\end{tabular}




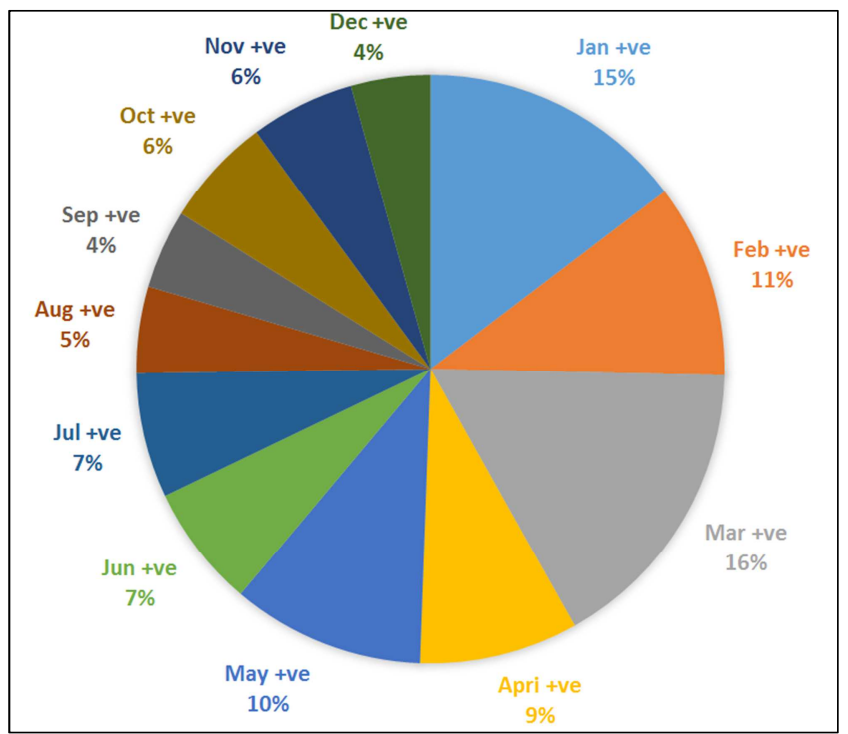

Figure 2. Monthwise.

Table 2. Month wise incidence per population from January to December.

\begin{tabular}{lllllll}
\hline Month & $\begin{array}{l}\text { Total } \\
\text { Suspects }\end{array}$ & $\begin{array}{l}\text { Total } \\
+ \text { vie }\end{array}$ & $\begin{array}{c}\text { Total } \\
\text {-vie }\end{array}$ & Male +vie & Female +vie & Total \\
\hline January & 379 & 141 & 238 & 62 & 79 \\
February & 340 & 103 & 237 & 49 & 54 \\
March & 410 & 159 & 251 & 75 & 84 & \\
April & 327 & 84 & 243 & 35 & 49 \\
May & 529 & 102 & 427 & 63 & 39 \\
June & 429 & 65 & 364 & 37 & 28 & 4253 \\
July & 344 & 66 & 278 & 25 & 41 & \\
August & 312 & 46 & 266 & 20 & 26 \\
September & 275 & 42 & 233 & 27 & 15 & \\
October & 290 & 58 & 232 & 39 & 19 & 26 \\
November & 310 & 55 & 255 & 29 & 27 \\
December & 308 & 42 & 266 & 15 & & \\
\hline
\end{tabular}

\section{Discussion}

Typhoid is one the real pushed in Khyber Pakhtunkhwa, in the present study, we found females suffering predominantly as compared to men, comparable finding a report concentrate on Khyber Pakhtunkhwa and in opposition to finds of research report completed in Iran [9-10]. One of the conceivable reasons why females are more influenced than men are that as youngsters are more helpless to typhoid disease thus typhoid minding obligations of women make them extra vulnerable to tainting [11]. Typhoid fever is still predominant in country territories are inferable from the lack of safe drinking and supply of water, cleanliness is poor and sullied nourishment. Typhoid fever is a standout amongst essential irresistible illnesses of South East Asian nations like Pakistan as it has been in charge of bringing about an extraordinary rate of hopelessness and mortality in this nation. Numerous cases have been accounted for all through the entire year. Like other Asian countries; typhoid fever can be a critical pointer of the financial state of the populace [12]. Sarwari \& Sulaiman in 2007 reported about the worldwide the most notorious hotspots for typhoid fever are Pakistan,
India, Nepal, Peru, Indonesia, Egypt and Mexico [13].

Keeping in view the consequences of this study it can be incidental that legitimate provided of hygienic drinking water, better sewerage framework and inoculation, alongside authoritarian ordering and appropriate focusing of the helpless age gatherings, is thought to be a powerful tool in controlling this ailment in Khyber Pakhtunkhwa Pakistan. Remain that as it may, this is insufficient we have need of better arranging and destruction projects to defeat this malady in the capital city as well as all through the Pakistan.

\section{Conclusion}

Based on the above findings, it may be concluded that higher incidence of typhoid fever was found, especially in women which is the important part of our society and responsible for the family and majorly play a Pivotal role in the life of her children. So Villager of Charsadda, the area of District Mardan kpk, Pakistan who consumed unsafe water and food from sources will be in more risk.

\section{Acknowledgements}

The authors are thankful to Abdul Wali Khan University Mardan.

\section{References}

[1] A. Andino and I. Hanning, 2015. Salmonella Enteric: Survival, Colonization, and Virulence Differences among Serovars: Hindawi Publishing Corporation e Scientific World Journal, 16 pages.

[2] Steady Mushayabasc. A simple epidemiology model for typhoid with saturated incidence rate \& treatment effect. Intl. J. Mathematical Computation, Electrical computer \& Physical, engineering, Vol: 6 No, 6, 2012.

[3] Shah, S. M., M. Yousafzai, N. B. Lakhani, R. A. Chotani and G. Nowshad, 2003. Prevalence and correlates of diarrhea, Indian Journal of Pediatrics, 70 (3): 207-211.

[4] Warren Levinson, Review of Medical Microbiology \& Immunology, (13 ${ }^{\text {th }}$ edit) ISBN: 978-0-07-181812-4.

[5] p. A. Grimont and F. X. Weill, Antigenic Formulae of the Salmonella Serovars, WHO Collaborating Centre for Reference and Research on Salmonella, Institut Pasteur, Paris, France, 2007.

[6] Masoumi, A. H., N. Aghili, M. M. Gouya \& M. Nabavi 2013. From 1962-2011 Epidemic of Typhoid Fever in Iran during Last Five Decades, Iranian Journal of Publ Health, 42 (1); 33-38.

[7] Usman Ayub, Amar Alik Khattak, Farakh Javeed, Afshan Saleem, Nazeem Hussain, Najam, Siddiqui \& Azam Hayat, 2015. The incidence of Typhoid Fever in Islamabad Pakistan, Toxicological Journal of American-Eurasian 7.25 years after Vi typhoid vaccine efficacy study, affects a significant number of population in Nepal, Plo. 1., 9 (1): e77974.

[8] Khosla, S. N. Changing pattern of typhoid. Asian Med. J., 1982; 25 (3):185.98. 
[9] Ochiai RL, Wang XY, Von Siedlein L et al. (2005) Salmonella Paratyphi A rates, Asia. Emerg Infect Dis 11 (11):1764-1766.

[10] Ochiai RL, Acosta CJ, Danovaro-Holliday MC et al. (2008) A study of typhoid fever in five Asian countries: disease burden and implications for control. Bull World Health Organ 86 (4):260-68.

[11] B. Singh, Sinha, A., M. Rao, S. Sood, V. P. Reddaiah, S. Sazawal A. Naficy, J. D. Clemens \& M. K. Bhan, R. Kumar 1999. Typhoid fever in children aged less than 5 years, Lancet,
354 (9180): 734-737.

[12] Bajracharya, D., M. I. Khan, A. Pach, P. Shrestha, N. Joshi, S. R. Upreti, T. Wierzba, M. Puri, S. Sahastrabuddhe \& R. L. Ochiai, 2014.

[13] Sulaiman, K. \& A. R. Sarwari, 2007. Culture-confirmed typhoid fever \& preg, Intl. J. Infect. Dis., 11 (4): 337-341. 